\title{
Confirmation of morphophysiological dormancy in sandalwood (Santalum album, Santalaceae) seeds
}

\author{
M.M. Dileepa M. Jayawardena ${ }^{1}$, K.M.G. Gehan Jayasuriya ${ }^{1,2 *}$ and Jeffrey L. Walck ${ }^{3}$ \\ ${ }^{\prime}$ Department of Botany, Faculty of Science, University of Peradeniya, Peradeniya. \\ ${ }^{2}$ Postgraduate Institute of Science, University of Peradeniya, Peradeniya. \\ ${ }^{3}$ Evolution and Ecology Group, Department of Biology, Middle Tennessee State University, Murfreesboro, TN, USA.
}

Revised: 15 September 2014; Accepted: 22 January 2015

\begin{abstract}
Indian sandalwood (Santalum album L.) is a hemi-parasitic angiosperm tree grown in India, Indonesia and Sri Lanka primarily for its economically valuable santalum oil. Although the seeds of this species have been reported to have morphophysiological dormancy (MPD), the occurrence of MPD in them or in Santalaceae has never been confirmed. Thus, the present study was conducted with the objective of identifying the class of dormancy present in $S$. album seeds. Ripened fruits of $S$. album collected from trees in Peradeniya, Sri Lanka were used to study the (1) imbibition and germination of non-scarified and scarified seeds, (2) effects of ambient laboratory conditions, gibberellic acid $\left(\mathrm{GA}_{3}\right)$ and dry storage on germination and (3) embryo:seed length (E:S) ratio for fresh seeds and for seeds soon after radicle emergence. Nonscarified and scarified seeds readily imbibed water. Increased germination with $\mathrm{GA}_{3}$ indicated a physiological component to dormancy, and increased E:S ratio prior to radicle emergence revealed an additional morphological component. Thus, we confirmed the occurrence of MPD in S. album, and suggest that the level is non-deep simple.
\end{abstract}

Keywords: Embryo growth, morphophysiological dormancy, Santalaceae, Santalum album, underdeveloped embryo.

\section{INTRODUCTION}

Indian sandalwood (Santalum album L.), a member of the family Santalaceae is a hemi-parasitic tree native to India, Indonesia and Sri Lanka and cultivated elsewhere in the tropical/subtropical Asian-Pacific region (Philcox, 1999). The aromatic wood is used for chests and the oil distilled from the heartwood is used in perfume-making and traditional aryuvedic medicine while ground wood is used in cosmetics (Mabberley, 2008). Hence, cultivation of $S$. album is highly profitable in Asia. However, the propagation of $S$. album is difficult since germination is usually poor and highly variable and the germination time exceeds 12 months (Annapurna et al., 2005; Singh et al., 2013).

Clarke and Doran (2012) have stated that no exact cause has been identified for the dormancy of S. album and speculated that the seeds of this species might have an exogenous kind of dormancy. However, Baskin and Baskin (1998) inferred that the seeds of this species have physiological dormancy (PD) or perhaps morphophysiological dormancy (MPD), i.e. seeds have a minute embryo that must elongate inside the seed before, during or after the loss of PD. Their inference was based on the facts that seeds required (1) warm stratification for dormancy loss (Srimathi \& Rao, 1969) and (2) a relatively long period to germinate (Beniwal \& Singh, 1989). Embryos inside $S$. album seeds are minute (Rangaswamy \& Rao, 1963), as are those of other species in Santalaceae (Martin, 1946), but whether they grow before radicle emergence is unknown. Additional information supports that the seeds of Santalum species are dormant at maturity and have a physiological component to their dormancy: germination increases with (1) gibberellic acid ( $\left.\mathrm{GA}_{3}\right)$ (Nagaveni \& Srimathi, 1980; Ananthapadmanabha et al., 1988; Hirano, 1990; Loveys \& Jusaitis, 1994; Cromer \& Woodall, 2007; Nikam \& Barmukh, 2009; Gamage et al., 2010) and (2) with removal of the fruit wall since the embryo has a low growth potential (Sahai \& Shivanna, 1984; Loveys \& Jusaitis, 1994; Woodall, 2004; Cromer \& Woodall, 2007). In contrast, Prasetyaningtyas (2007) reported that the fruit pulp apparently contains inhibitors but the extracted clean seed has no known dormancy. 
S. album seeds do not germinate readily in nurseries and takes 2-3 months to start germination (Subasinghe, 2013). Although $\mathrm{GA}_{3}$ treatment has shown to improve the germination percentage of sandalwood seeds(Etampawala et al., 2000; Annapurna et al., 2005; Gamage et al., 2010; Doran, 2012), it is not used in producing S. album seedlings as $\mathrm{GA}_{3}$ is not used economically. Generally, large numbers of sandalwood seeds are planted in nursery beds and early emerging seedlings (after 2-3 months) are collected for plantations (personal communication with sandalwood growers). By selecting the portion of the seed lot that readily germinates, a large number of seeds remain un-germinated and probably dormant. A potential problem that may arise from the long term practice of this cultivation method would be reduced genetic variability in plantations. Thus, the best way to produce seedlings, specially for reforestation activities, would be to use seeds that are non-dormant, [i.e. the proper dormancy break treatment(s) have already been applied], ensuring germination of increased number of seeds. The correct identification of the class of dormancy in seeds of this species is an important first step to determine suitable dormancy breaking treatments.

The main objective of the present study was to determine the class of dormancy in S. album seeds. To do this, we decided to do a full-scale examination and check the presence (or absence) of all dormancy classes (Baskin \& Baskin, 2004). The following were studied: (1) imbibition of non-scarified $v s$ scarified seeds to test for physical dormancy (PY), (2) the effects of laboratory conditions (which were near-natural), dry storage, and gibberellic acid $\left(\mathrm{GA}_{3}\right)$ on germination of seeds to assess for PD and (3) embryo elongation prior to radicle emergence to examine morphological dormancy (MD). Combinational dormancy would be present if the seeds have PY in conjunction with PD, and MPD would occur if the seeds have PD + MD. Thus, all experiments taken together would identify the class of dormancy in S. album.

\section{METHODS AND MATERIALS}

\section{Collection of seeds and general laboratory procedures}

Ripened (dark purple) fruits were picked from five mature trees at the University of Peradeniya, Sri Lanka during June 2011 and June 2012. These collections were not mixed but used in separate experiments. Fruits were de-pulped, air dried for $2 \mathrm{~h}$ and stored dry in plastic bottles until used in experiments, which were initiated within 2 wks after the collection date. A de-pulped fruit consisted of the endocarp and the true seed (hereafter, referred to as a seed).

The ambient temperature and relative humidity in the laboratory were $\sim 27{ }^{\circ} \mathrm{C}$ and $80 \%$, respectively, which approximated the conditions out-of-doors in Peradeniya, Sri Lanka. Light during the day $(\sim 10 \mathrm{~h})$ was provided by diffuse sunlight through windows and white fluorescent lights in the room; all the lights in the room were turned off at night (hereafter, alternating light/dark). Unless otherwise stated, experiments were conducted on tissue papers moistened with distilled water in $9 \mathrm{~cm}$ diameter Petri dishes. The dishes were placed on top of a laboratory bench and the seeds received the alternating light/dark or kept in complete darkness. Complete darkness was provided by wrapping the Petri dishes with black varnish paper. Manual scarification of seeds was done using a scalpel. For each experiment, seeds were selected randomly. Radicle emergence (at least $1 \mathrm{~mm}$ ) was the criterion for germination.

\section{Imbibition of seeds}

Two samples of 15 non-scarified (intact) and 15 manually scarified seeds each were weighed individually with a digital balance to the nearest $0.001 \mathrm{~g}$. The seeds were placed on moist tissue papers in Petri dishes, which were positioned on a bench in light/dark conditions. The seeds were retrieved from the Petri dishes at time intervals shown in Figure 1. When retrieved, they were lightly blotted to remove excess water, reweighed individually and returned to the Petri dishes until the next weighing for a total of $26 \mathrm{~d}$.

\section{Effect of laboratory conditions on germination}

Two samples with three replicates of 15 non-scarified seeds each and two samples of 15 manually scarified seeds each were placed on moist tissue papers in Petri dishes. The dishes were positioned on a bench with one sample from each seed condition (i.e. non-scarified or scarified) given the alternating light/dark, and the other sample was kept in darkness. Seed samples in alternating light/dark were observed at 2-d intervals for $30 \mathrm{~d}$, while the samples kept in darkness were observed after $30 \mathrm{~d}$ (at the end of the experiment).

\section{Effect of gibberellic acid on germination}

Three samples with three replicates containing 15 nonscarified seeds each and three samples with 15 manually scarified seeds each were placed on tissue papers moistened with distilled water and $100 \mathrm{ppm}$ or $500 \mathrm{ppm}$ 
$\mathrm{GA}_{3}$ (i.e. each seed condition was tested on water and on both $\mathrm{GA}_{3}$ concentrations). The samples were positioned on a bench in alternating light/dark. The seeds were observed as mentioned previously.

\section{Effect of dry storage on germination}

Eight samples with three replicates of 15 (non-scarified) seeds each were stored dry in plastic bottles in the laboratory. Two samples each were retrieved after 2, 4, 7 and 11 months of storage and tested for germination on tissue papers moistened with distilled water or 500 ppm $\mathrm{GA}_{3}$. The tests were conducted under the conditions mentioned above and the observations were made as mentioned previously.

\section{Change of embryo length : seed length (E:S) ratio}

Two studies were conducted. The first study was done to monitor the development of embryo within the seed under laboratory conditions. Two samples of 24 (non-scarified) seeds each were placed on tissue papers in Petri dishes moistened with distilled water or with 500 ppm GA $_{3}$; the dishes were positioned on a bench in alternating light/ dark. Three seeds each were retrieved from each sample at $0,2,7,8,11,14,21$ and $22 \mathrm{~d}$ after the experiment was initiated until the seeds started to germinate. The 0 day measurement was done on the seeds that imbibed for $24 \mathrm{~h}$ on both solutions. The seeds were cut open with a razor blade, and the embryo length (E) and seed length (S) were measured with a ruler to the nearest $1 \mathrm{~mm}$, and $\mathrm{E}: \mathrm{S}$ ratio was calculated. Seeds were photographed using a digital camera (Nikon 3100D) with a $40 \mathrm{~mm}$ macro lens.

The second study compared the E:S ratio of the seeds before and soon after germination. Two samples with 15 seeds each were established. Seeds in one of the two samples were placed on tissue papers moistened with distilled water and kept for $24 \mathrm{~h}$ on a bench in alternating light/dark. After $24 \mathrm{~h}$, the embryo and seed lengths were measured and the E:S ratio calculated. Seeds in the other sample were placed on tissue papers moistened with 500 ppm $\mathrm{GA}_{3}$. The E:S ratio was determined in these seeds when the radicle had emerged by $<0.5 \mathrm{~mm}$.

\section{Statistical analyses}

Statistical analyses were conducted using MINITAB software (MINITAB ${ }^{\circledR}$ release 14.1, MINITAB Inc., Quality Plaza, PA, USA). Percentage imbibition data and percentage germination data were arcsine square root transformed prior to analyses. Imbibition of non-scarified and scarified seeds was analysed with a pooled t-test.
Two-way ANOVAs were conducted to analyse the results of the following experiments: laboratory conditions [scarification (non-scarified $v s$ scarified) and light regime (alternating light/dark $v s$ complete darkness) as factors]; $\mathrm{GA}_{3}$ [solution (water vs two $\mathrm{GA}_{3}$ concentrations) and scarification as factors], and dry storage [solution (water vs $\mathrm{GA}_{3}$ ) and storage time as factors].

\section{RESULTS}

\section{Imbibition of seeds}

Mass increase of non-scarified seeds was not significantly different from that of manually scarified seeds on the last day of measurement $(\mathrm{t}=0.64, \mathrm{p}=0.53)$. The mass of both non-scarified and manually scarified seeds increased rapidly during the first 100 hours and then no (or little) further increase of mass was observed (Figure 1). The mass of non-scarified seeds increased $20-22 \%$, while that of manually scarified seeds increased $27-29 \%$.

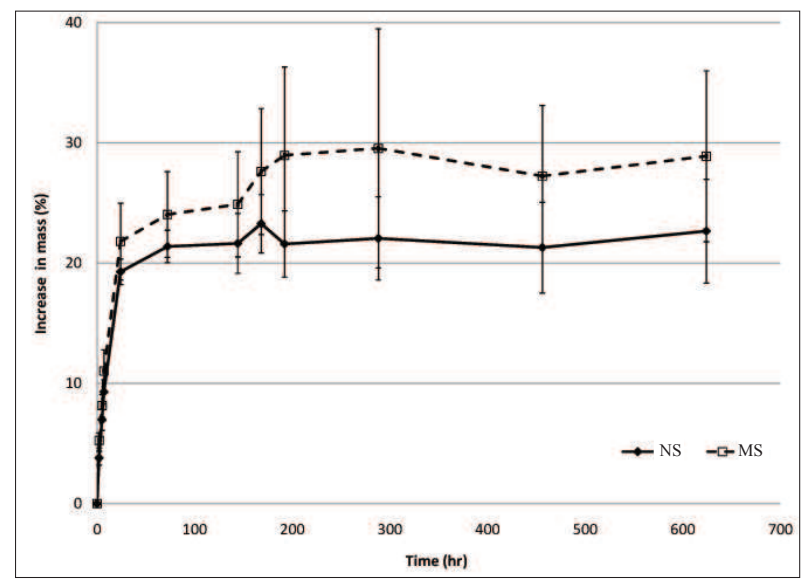

Figure 1: Mass increase during imbibition of non-scarified (intact) fresh (NS) and manually scarified fresh (MS) S. album seeds at ambient laboratory temperature and relative humidity conditions. Error bars $\pm \mathrm{SD}$.

\section{Effect of laboratory conditions on germination}

Neither scarification $(\mathrm{F}=1.00, \mathrm{p}=0.34)$ nor light regime $(\mathrm{F}=0.98, \mathrm{p}=0.37)$ significantly affected the germination, and the response for non-scarified $v s$ scarified seeds was similar between light regimes (interaction, $F=1.00$, $\mathrm{p}=0.34$ ). For non-scarified seeds, none germinated in either light regimes (data not shown). For scarified seeds, only $3.3 \pm 5.7 \%$ (mean \pm SD) germinated in light/dark and none did so in the darkness. 


\section{Effect of gibberellic acid on germination}

$\mathrm{GA}_{3}(\mathrm{~F}=72.43, \mathrm{p}<0.001)$ and scarification $(\mathrm{F}=15.87$, $\mathrm{p}=0.002)$ significantly affected germination, but the response to $\mathrm{GA}_{3}$ gradient [0 (distilled water) to 100 to 500 ppm $\left.\mathrm{GA}_{3}\right]$ was similar between non-scarified $v s$ scarified seeds (interaction, $\mathrm{F}=2.74, \mathrm{p}=0.058$ ). Treatment with $\mathrm{GA}_{3}$ specially with $500 \mathrm{ppm}$ for both non-scarified and scarified seeds significantly enhanced the germination (Figure 2).

\section{Effect of dry storage on germination}

Although storage time $(\mathrm{F}=3.30, \mathrm{p}=0.031)$ and $\mathrm{GA}_{3}$ $(\mathrm{F}=169.90, \mathrm{p}<0.001)$ significantly affected germination, the response to different solutions remained relatively constant over time (interaction, $\mathrm{F}=0.93, \mathrm{p}=0.467$ ). Germination of seeds placed on distilled water was low, and that of the seeds on $\mathrm{GA}_{3}$ was high regardless of the storage time (Figure 3).

\section{Change of embryo length:seed length (E:S) ratio}

The initial mean $( \pm \mathrm{SD}) \mathrm{E}: \mathrm{S}$ ratio of the seeds was 0.61 \pm 0.10 and it was $0.87 \pm 0.06$ within $<24$ hours after

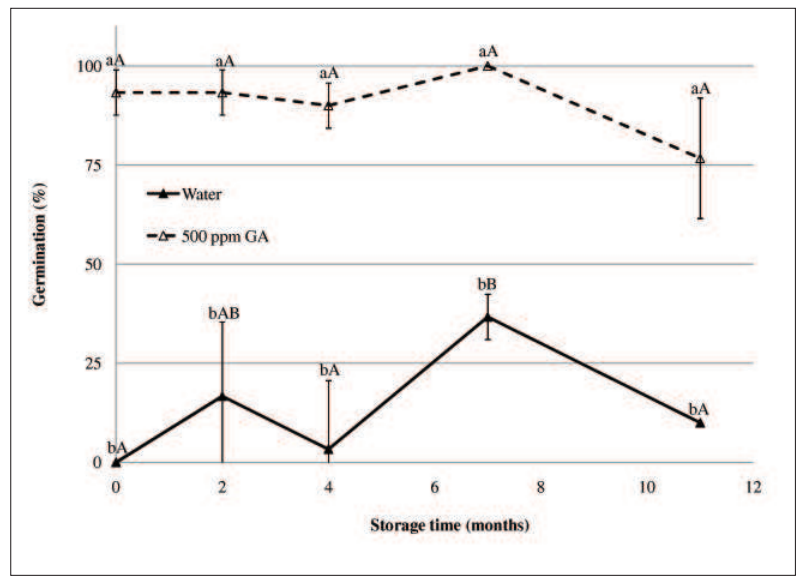

Figure 3: Germination of $S$. album seeds stored dry in plastic bottles for $0,2,4,7$ and 11 months at ambient laboratory temperature and relative humidity conditions. Germination experiments were conducted on distilled water or on $500 \mathrm{ppm}$ gibberellic acid $\left(\mathrm{GA}_{3}\right)$ at ambient laboratory temperature and alternating light/dark conditions. Different lowercase letters indicate significant differences between solutions for the same storage time and different uppercase letters indicate significant differences among storage times within the same solution (LSD mean separation, $\mathrm{p}=0.05$ ). Error bars $\pm \mathrm{SD}$.

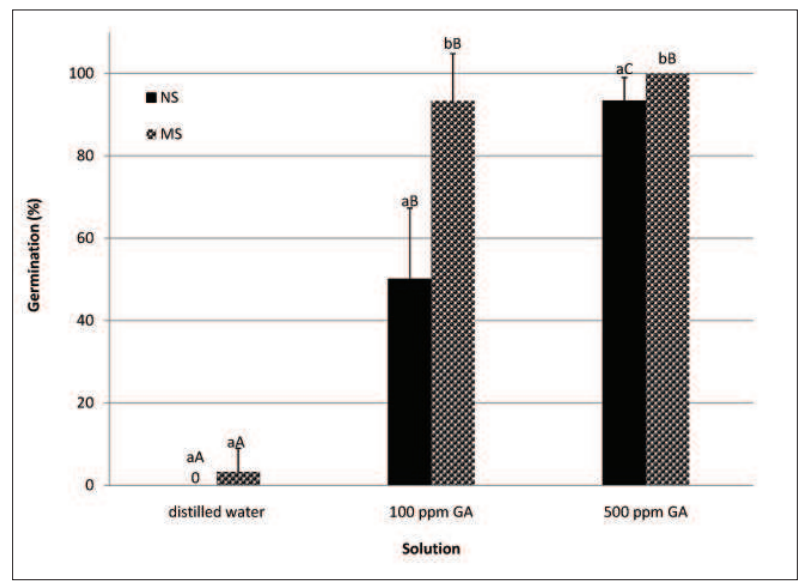

Figure 2: Germination of non-scarified (NS) and manually scarified (MS) S. album seeds on three solutions: distilled water, $100 \mathrm{ppm} \mathrm{GA}_{3}$ and $500 \mathrm{ppm} \mathrm{GA}_{3}$ at ambient laboratory temperature and alternating light/dark conditions for 30 days. Different lowercase letters indicate significant differences between NS/MS treatments within the same solution and different uppercase letters indicate significant differences among solutions within the same NS or MS treatment (LSD mean separation, $\mathrm{p}=0.05$ ). Error bars $+\mathrm{SD}$.

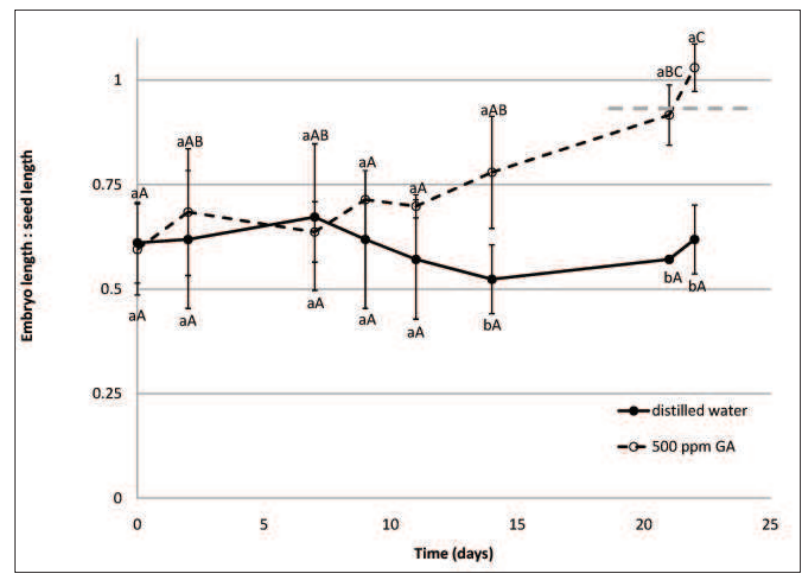

Figure 4: Embryo:seed length ratio of S. album on distilled water

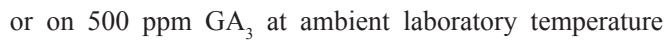
and alternating light/dark conditions. Different lowercase letters indicate significant differences between solutions at the same measurement time and different uppercase letters indicate significant differences among measurement times within the same solution (LSD mean separation, $\mathrm{p}=0.05$ ). Dashed line depicts the E:S ratio within $<24$ hours of radicle emergence. Error bars $\pm \mathrm{SD}$. 
germination (Figures 4, 5A, 5B). Thus, the embryo elongated $\sim 40 \%$ within the seed before radicle emergence. E:S ratio did not increase over the 22-day period for seeds on distilled water (Figure 4). In contrast, the ratio remained nearly constant up to day 11 for seeds on $\mathrm{GA}_{3}$, then increased dramatically and reached $0.91 \pm 0.07$ at day 22 at which $100 \%$ germination was observed. Cotyledons, plumule and epicotyl continued to grow until the plumule emerged, which occurred after 7 - 10 days from radicle emergence (Figure 5C and D). Compared to the drawings and descriptions in Martin (1946) and in Baskin and Baskin (2007), the embryo shape in $S$. album seeds can be classified as linear.

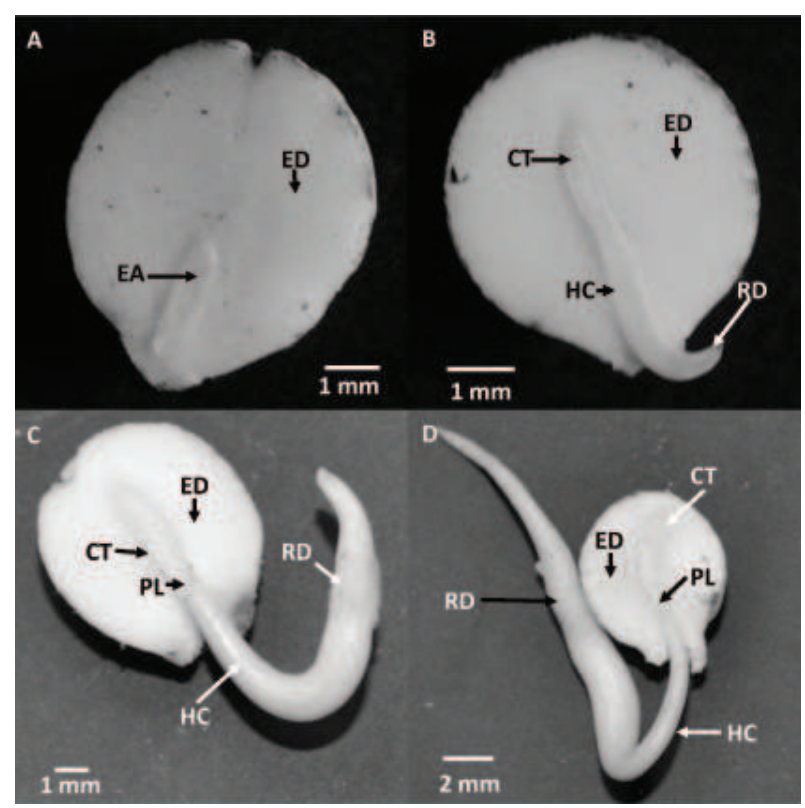

Figure 5: Stages of embryo growth for S. album seeds: 1 hour after imbibition at ambient laboratory temperature and relative humidity conditions (A); within $<24 \mathrm{~h}$ of radicle emergence (B); 5 days after radicle emergence (C) and 7 days after radicle emergence (D)

CT, cotyledons; EA, embryo axis; ED, endosperm; HC, hypocotyl; PL, plumule; RD, radicle

\section{DISCUSSION AND CONCLUSION}

A very low percentage of fresh (both non-scarified and scarified) S. album seeds germinated on distilled water in alternating light/dark or in darkness during 30 days. Baskin and Baskin (2003) suggested a 30-day cut-off to distinguish between the seeds that are non-dormant versus the seeds that have some class of dormancy. Since the majority of $S$. album seeds did not germinate within 30 days, we conclude that they are dormant at maturity. The results of the present study do not support Prasetyaningtyas's (2007) report that clean seeds have no known dormancy. Besides, we are uncertain as to what was meant by 'clean seed'. It would not be surprising if germination was enhanced following the removal of the fruit wall (i.e., using 'clean seed') since it provides a physical barrier for germination in Santalum species (Sahai \& Shivanna, 1984; Loveys \& Jusaitis, 1994; Woodall, 2004). However, this physical barrier does not prevent the imbibition of water. Non-scarified seeds of S. album readily imbibed water to the same extent and at about the same rate as scarified seeds. Thus, we can rule out the possibility of seeds having PY or PY + PD. This result is not too surprising since PY or PY + PD are not known to occur in seeds of any member of the Santalales (Baskin \& Baskin, 2003).

$\mathrm{GA}_{3}$ greatly enhanced the germination of both non-scarified and scarified seeds of $S$. album regardless of the length of dry storage. However, $100 \mathrm{ppm} \mathrm{GA}_{3}$ treatment was more effective for manually scarified seeds compared to intact seeds. The enhancement of germination of $S$. album seeds by $\mathrm{GA}_{3}$ has been reported by several other researchers (Etampawala et al., 2000; Annapurna et al., 2006; Gamage et al., 2010; Doran, 2012). Thus, the seeds of this species have a physiological component to dormancy that can be overcome with $\mathrm{GA}_{3}$. Seeds of $S$. album are similar to those of the other species with non-deep or intermediate levels of PD (as opposed to deep PD), since $\mathrm{GA}_{3}$-treated seeds readily germinated (Baskin \& Baskin, 2004). To distinguish between nondeep and intermediate levels of PD, information is needed on the temperature required for dormancy break, which was not tested in the present study. Non-deep PD is broken by warm or cold stratification, whereas intermediate PD needs cold stratification (Baskin \& Baskin, 2004). Moreover, scarification may promote germination in seeds with non-deep PD. Based on the study by Srimathi and Rao (1969) who reported that the seeds of S. album germinated at $24-27{ }^{\circ} \mathrm{C}$ (within the range of warm stratification) and our data, which showed that scarification enhanced germination, we suggest that the level of PD would be non-deep.

Embryos inside $S$. album seeds had to grow $\sim 40 \%$ prior to radicle emergence showing that they are 'underdeveloped' at maturity, i.e. they have distinguishable cotyledons and a radicle but they must elongate inside the seed before radicle emergence. Although Baskin and Baskin (2007) considered underdeveloped embryos to have an E:S ratio $<0.5$, the E:S ratio in S. album seeds was 0.61. Thus, the E:S ratio for the seeds of this species is slightly higher than that for the other species with linear underdeveloped embryos. 
Overall, the seeds of S. album also have a morphological component to dormancy and can be classified as having MPD, confirming the inference in Baskin and Baskin (1998). Several levels of MPD are recognised (Baskin \& Baskin, 2004), but most of them can be ruled out since warm stratification enabled embryo growth as judged by germination (Srimathi \& Rao, 1969). Thus, we suggest that the seeds of $S$. album have non-deep simple MPD.

Herein, we identified that the class of dormancy in S. album seeds is MPD, which can be effectively alleviated with $\mathrm{GA}_{3}$. The present study is the first time that MPD has been confirmed in S. album seeds, and to the best of our knowledge, in seeds of any Santalaceae species. Although additional work is needed, we suggest that the level of MPD in S. album seeds is non-deep simple. The study further confirms the effectiveness of $\mathrm{GA}_{3}$ treatment (soaking seeds in a $\mathrm{GA}_{3}$ solution prior to sowing them in nursery beds) on increasing the number of seeds that germinate for the establishment of S. album plantations. However, no promising low cost method to break the dormancy of S. album seeds was found. Luckily, the seeds can be stored dry in plastic bottles for about one year without a large impact on germination. However, even after dry storage the seeds should be treated with $\mathrm{GA}_{3}$ for germination.

\section{REFERENCES}

1. Ananthapadmanabha H.S., Nagaveni H.C. \& Rai S.N. (1988). Dormancy principals in sandal seeds (Santalum album Linn.). Myforest 24: 22 - 24.

2. Annapurna D., Rathore T.S. \& Somashekhar P.V. (2005). Impact of clones in a clonal seed orchard on the variation of seed traits, germination and seedling growth in Santalum album L. Silvae Genetica 5: 153 - 160.

3. Baskin C.C. \& Baskin J.M. (1998). Seeds: Ecology, Biogeography, and Evolution of Dormancy and Germination. Academic Press, San Diego, USA.

4. Baskin J.M. \& Baskin C.C. (2003). Classification, biogeography, and phylogenetic relationships of seed dormancy. Seed Conservation: Turning Science into Practice (eds. R.D. Smith, J.B. Dickie, S.H. Linnington, H.W. Pritchard \& R.J. Probert), pp. 518 - 544. The Royal Botanic Gardens, Kew, UK.

5. Baskin J.M. \& Baskin C.C. (2004). A classification system for seed dormancy. Seed Science Research 44: 1 - 16. DOI: http://dx.doi.org/10.1079/ssr2003150

6. Baskin C.C. \& Baskin J.M. (2007). A revision of Martin's seed classification system, with particular reference to his dwarf-seed type. Seed Science Research 17: 11 - 20. DOI: http://dx.doi.org/10.1017/S0960258507383189

7. Beniwal B.S. \& Singh N.B. (1989). Observations of the flowering, fruiting and germination behaviour of some useful forest plants of Arunachal Pradesh. Indian Forester 115: $216-227$.
8. Clarke B. \& Doran J. (2012). Review of Santalum album L. seed pre-germination treatment with a focus of low cost methods. Proceedings of the International Sandalwood Symposium, 21 - 24 October, 2012, Honolulu, Hawaii.

9. Cromer E.L. \& Woodall G. (2007). Breaking mechanical dormancy in quandong using silica gel and enhancing germination response using gibberellic acid. Alcoa World Alumina Australia 28: 1 - 10.

10. Doran J. (2012). Review of Santalum album seed pre-germination treatments with a focus on low cost methods. Proceedings of International Sandalwood Symposium, 21 - 24 October, 2012, Honolulu, Hawaii.

11. Etampawala E.R.L.B., Tennakoon K.U., Gunatilleke C.V.S., Gunatilleke I.A.U.N. \& Ekanayake S.P. (2000). Germination and seedling ecology of Santalum album L.. Proceedings and Abstract of the Annual Research Sessions University of Peradeniya, October 23, University of Peradeniya, p. 196.

12. Gamage Y.M.M., Subasinghe S.M.C.U.P. \& Hettiarachchi D.S. (2010). Change of seed germination rate with storage time of Santalum album L. (Indian sandalwood) seeds. Proceedings of the $15^{\text {th }}$ International Forestry and Environment Symposium (eds. D.M.H.S.K. Ranasinghe, B.M.P. Singhakumara, H.S. Amarasekera, N.J.G.J. Bandara, U.A.D.P. Gunawardana \& S.M.C.U.P. Subasinghe), volume 15, Department of Forestry and Environmental Science, University of Sri Jayewardenepura, pp. $279-281$.

13. Hirano R.T. (1990). Propagation of Santalum, sandalwood tree. USDA Forest Service General Technical Reports 122: $43-45$.

14. Loveys B.R. \& Jusaitis M. (1994). Stimulation of germination of quandong (Santalu macuminatum) and other Australian native plant seeds. Australian Journal of Botany 42: 565 - 574.

DOI: http://dx.doi.org/10.1071/BT9940565

15. Mabberley D.J. (2008). Mabberley's Plant Book, a Portable Dictionary of Plants, their Classification and Uses, $3^{\text {rd }}$ edition. Cambridge University Press, Cambridge, UK.

16. Martin A.C. (1946). The comparative internal morphology of seeds. American Midland Naturalist 36: 513 - 660.

DOI: http://dx.doi.org/10.2307/2421457

17. Nagaveni H.C. \& Srimathi R.A. (1980). Studies on germination of the sandal seeds, Santalum album Linn. II. chemical stimulant for germination. Indian Forester 106: $792-799$.

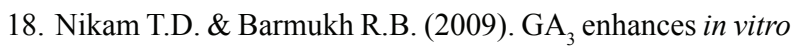
seed germination in Santalum album. Seed Science and Technology 37: 276 - 280 .

DOI: http://dx.doi.org/10.15258/sst.2009.37.2.02

19. Philcox D. (1999). Santalaceae. A Revised Handbook to the Flora of Ceylon (eds. M.D. Dassanayake \& F.R. Fosberg), pp. 199 - 201. CRC Press, Boca Raton, FL, USA.

20. Prasetyaningtyas M. (2007). Santalum album L. Seed Leaflet No. 116, pp. 1 - 2. Forest and Landscape Denmark, Hørsholm, Kongevej, Denmark.

21. Rangaswamy N.S. \& Rao P.S. (1963). Experimental studies on Santalum album L. -establishment of tissue culture of endosperm. Phytomorphology 13: 450 - 454. 
22. Sahai A. \& Shivanna K.R. (1984). Seed germination, seedling growth and haustorial induction in Santalum album, a semi-root parasite. Proceedings of the Indian Academy of Sciences 93: 571 - 580.

23. Singh C.K., Sandeep R.R., Patil V.R., Jaiswal P.S. \& Subhash N. (2013). Plant regeneration from leaf explants of mature sandalwood (Santalum album L.) trees under in vitro conditions. In vitro Cellular and Developmental Biology-Plant 49: 216 - 222.

DOI: http://dx.doi.org/10.1007/s11627-013-9495-y
24. Srimathi R.A. \& Rao P.S. (1969). Accelerated germination of sandal seed. Indian Forester 95: $158-159$.

25. Subasinghe S.M.C.U.P. (2013). Sandalwood research: a global perspective. Journal of Tropical Forestry and Enviornment 3: $1-8$.

26. Woodall G.S. (2004). Cracking the woody endocarp of Santalum spicatum nuts by wetting and rapid drying improves germination. Australian Journal of Botany 52: $163-169$.

DOI: http://dx.doi.org/10.1071/BT03007 